\title{
Once-weekly albiglutide in the management of type 2 diabetes: patient considerations
}

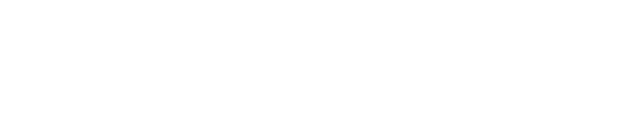

\author{
Heather N Woodward' \\ Sarah L Anderson ${ }^{2}$ \\ 'Centura St. Anthony's Hospital, \\ Lakewood, CO, USA; '2Department \\ of Clinical Pharmacy, University of \\ Colorado Skaggs School of Pharmacy \\ and Pharmaceutical Sciences, Aurora, \\ CO, USA
}

\begin{abstract}
This review describes the pharmacologic, pharmacokinetic, and pharmacodynamic properties of albiglutide, as well as its clinical efficacy and safety. Albiglutide is a novel, once-weekly, injectable glucagon-like peptide-1 receptor agonist for the treatment of type 2 diabetes. The European Commission recently granted marketing authorization for the drug in the European Union and on April 15, 2014, the US Food and Drug Administration approved albiglutide (Tanzeum ${ }^{\mathrm{TM}}$ [GlaxoSmithKline LLC, Wilmington, DE, USA]) to improve glycemic control in adults with type 2 diabetes. Albiglutide has been studied in Phase I, II, and III clinical trials. In the Phase III clinical trials, known as the Harmony series, weekly dosing of albiglutide demonstrated reductions in fasting plasma glucose, postprandial plasma glucose, and glycated hemoglobin, and was associated with weight loss. In all phases of the clinical trials, albiglutide administered once weekly showed a safety and tolerability profile similar to that of placebo, with mild gastrointestinal-related complaints and injection site erythema being the most commonly encountered adverse effects. Compared with pioglitazone and liraglutide, albiglutide has been shown to be clinically less effective. However, it offers the benefit of weight loss that pioglitazone does not, with fewer gastrointestinal side effects than liraglutide. As guidelines continue to advocate for patient-centered treatment strategies, once-weekly albiglutide will be an important addition to the growing armamentarium of treatment options for adults with type 2 diabetes needing target glycemic control.
\end{abstract}

Keywords: albiglutide, glucagon-like peptide 1 receptor agonist, drug therapy, type 2 diabetes mellitus

\section{Introduction}

Despite the advances in treatment available for type 2 diabetes mellitus, nearly $50 \%$ of patients with this condition fail to meet their glycemic target. ${ }^{1}$ The barriers underlying this issue are several-fold, and include patient nonadherence to therapy and therapeutic inertia in a chronic disease state that frequently requires escalation of therapy. ${ }^{1}$ Therapies that promote patient adherence and are synergistic with other antihyperglycemic agents are necessary to overcome these barriers.

Hyperglycemia is known to cause microvascular complications in patients with type 2 diabetes mellitus and trends have been observed between hyperglycemia and cardiovascular disease. ${ }^{1,2}$ Despite these known risks, an exact treatment algorithm to manage hyperglycemia does not exist. Current guidelines support initiation of lifestyle modifications plus metformin as first-line monotherapy, and the treatment algorithm for adding or changing agents beyond that should be based on patient-specific factors. ${ }^{2,3}$ One class of highly-effective agents that can be utilized for additional glycemic control are the glucagon-like peptide-1 (GLP-1) receptor agonists. As the native incretin hormone GLP-1, these agents activate the GLP-1 receptor to increase glucose-dependent insulin secretion, decrease glucose-dependent glucagon secretion, slow gastric
Correspondence: Sarah L Anderson Mail Stop C238, I 2850 E Montview Blvd, Room V20-2 I 29, Aurora, CO 80045, USA $\mathrm{Tel}+\mathrm{I} 3037245926$

Fax + I 3037242627

Email sarah.anderson@ucdenver.edu 
emptying, and increase satiety. ${ }^{3}$ GLP-1 receptor agonists decrease glycated hemoglobin $\left(\mathrm{HbA}_{1 \mathrm{C}}\right)$, cause weight loss, and are low-risk for causing hypoglycemia. ${ }^{2,3}$

Albiglutide (Tanzeum ${ }^{\mathrm{TM}}$ ) is a once-weekly GLP-1 receptor agonist developed by GlaxoSmithKline LLC (Wilmington, DE, USA) for the treatment of type 2 diabetes mellitus. The manufacturer received marketing authorization from the European Commission on March 26, 2014, and expects to launch albiglutide in several European countries by the end of 2014. ${ }^{4}$ On April 15, 2014, albiglutide was approved by the US Food and Drug Administration for improvement of glycemic control along with diet and exercise in adults with type 2 diabetes mellitus. ${ }^{4}$ Albiglutide is a novel compound comprised of a dipeptidyl peptidase-IV (DPP-IV)-resistant GLP-1 dimer fused to human albumin. ${ }^{5-7}$ The fusion to human albumin extends its half-life and makes onceweekly dosing possible. ${ }^{8}$ Less frequent dosing is a potential advantage over other GLP-1 receptor agonists that require once-daily or even twice-daily injections. ${ }^{9-11}$ An additional perceived benefit with albiglutide is that its large molecular size leads to less central nervous system penetration and thus fewer gastrointestinal adverse effects. ${ }^{12}$ This review discusses the pharmacology, efficacy, safety, and patient considerations regarding the use of albiglutide.

\section{Pharmacology Mechanism of action}

In the human body, native GLP-1 released from enteroendocrine L-cells post-meal stimulates glucose-dependent insulin secretion and suppresses glucose-dependent glucagon secretion. ${ }^{13}$ Additionally, GLP-1 slows gastric emptying and subsequently reduces food intake, leading to modest weight loss. ${ }^{13}$ However, native GLP-1 is actively degraded by DPP-IV, which limits its therapeutic potential. Albiglutide is a GLP-1 receptor agonist created by the fusion of two 30 amino acid sequence repeats of human GLP-1 molecules to recombinant human albumin..$^{5-7,12}$ An amino acid substitution (alanine at position 8 to glycine) confers resistance to DPP-IV, and the dual amino acid sequence fusion to human albumin enhances potency and extends the half-life to 5-8 days, making once-weekly dosing possible..$^{5-8,12}$

\section{Pharmacokinetics}

Several Phase I and Phase II studies have characterized the pharmacokinetic properties of albiglutide in healthy volunteers, Japanese patients with type 2 diabetes, and in non-Japanese patients with type 2 diabetes. ${ }^{12,14-16}$
Bush et al studied 39 healthy subjects (95\% Hispanic/ Latino) who received either placebo or escalating doses of albiglutide subcutaneously on day $1(0.25 \mathrm{mg}$ to $80 \mathrm{mg})$ and day 8 (1 $\mathrm{mg}$ to $104 \mathrm{mg}$ ). The median time taken to reach peak plasma concentration ranged from 2.3 to 4.0 days and the elimination half-life after day 8 ranged from 6.0 to 8.0 days for all doses. ${ }^{12}$

Seino et al studied 40 Japanese patients with type 2 diabetes mellitus who received either albiglutide $15 \mathrm{mg}$ weekly, $30 \mathrm{mg}$ weekly, $50 \mathrm{mg}$ biweekly, or $100 \mathrm{mg}$ monthly over a 4-week period. The elimination half-life was slightly shorter than in the Phase I study by Bush et al at a median of 5.3 (range 4.6-5.9) days. The plasma clearance and volume of distribution of albiglutide were calculated to be $68.7 \mathrm{~mL} /$ hour and $12.6 \mathrm{~L}$, respectively. ${ }^{14}$

Studies by Rosenstock et al and Matthews et al evaluated the use of albiglutide in non-Japanese patients with type 2 diabetes mellitus. Matthews et al evaluated both the pharmacokinetics and pharmacodynamics of albiglutide in two separate studies, ie, a dose-escalation study and an injection site study. In the dose-escalation study, albiglutide was readily absorbed with a median lag time of $3.5(0.00-18.5)$ hours in patients who received a $9 \mathrm{mg}$ dose and $0.00(0.00-8.5)$ hours in patients who received $16 \mathrm{mg}$ and $32 \mathrm{mg}$ doses. This means the larger doses of albiglutide (16 mg and $32 \mathrm{mg}$ ) had excellent bioavailability. The area under the curve for plasma drug concentration at week 1 and week 2 demonstrated slow drug accumulation, a trend similar to that seen in the study by Seino et al. The time taken to reach peak plasma concentration ranged from 2.99 to 5.0 days, and the elimination half-life was 5.73-6.8 days. ${ }^{14,15}$

The injection site study evaluated the relative bioavailability of a single dose (16 mg or $64 \mathrm{mg}$ ) of albiglutide in the arm, leg, or abdomen in 46 patients. There were no significant effects of injection site on the pharmacokinetic parameters. A dose-dependent increase in elimination half-life and plasma area under the curve for the drug was observed. ${ }^{15}$

Rosenstock et al evaluated a larger cohort of 356 patients with type 2 diabetes mellitus who received placebo or albiglutide weekly (4 mg, $15 \mathrm{mg}$, or $30 \mathrm{mg}$ ), biweekly (15 mg, $30 \mathrm{mg}$, or $50 \mathrm{mg}$ ) or monthly (50 mg or $100 \mathrm{mg}$ ). Albiglutide reached steady state within 4-5 weeks and had an elimination half-life of approximately 5 days. ${ }^{16}$

These five trials established that albiglutide is a drug amenable to once-weekly dosing by demonstrating an elimination half-life of 5-8 days with peak plasma levels achieved in 2.3-5 days. ${ }^{12,14-16}$ 


\section{Pharmacodynamics}

The pharmacodynamic parameters that have been evaluated for albiglutide include its effects on glucose, insulin, C-peptide, glucagon, fasting plasma glucose, postprandial plasma glucose, free fatty acids, and fructosamine. Healthy subjects who received increasing doses of albiglutide showed a trend of dose-dependent reduction in glucose and fructosamine levels. In these healthy subjects, there were no dosedependent effects seen for glucagon, insulin, or C-peptide concentrations. ${ }^{12}$ In a study of Japanese patients with type 2 diabetes mellitus who were randomized to receive albiglutide $15 \mathrm{mg}$ or $30 \mathrm{mg}$ once weekly, $50 \mathrm{mg}$ every 2 weeks, or $100 \mathrm{mg}$ monthly, the mean weighted glucose (area under the curve) after 4 weeks was significantly decreased in all patients except for those who received the $100 \mathrm{mg}$ dose (all $P \leq 0.002$ except for the $100 \mathrm{mg}$ dose, $P=0.065$ ). The placebo-adjusted mean plasma glucose was also significantly decreased in all groups except for the $100 \mathrm{mg}$ group (all $P \leq 0.001$ except for the $100 \mathrm{mg}$ dose, $P=0.613$ ). These results were reproduced 2 weeks after the treatment period ended. Greater fluctuations in fasting plasma glucose were seen with biweekly and monthly doses, whereas once-weekly doses of albiglutide produced more consistent results. ${ }^{14}$ In the second study, significant reductions in placebo-adjusted least square means for the glucose $(\mathrm{mg} / \mathrm{dL})$ area under the curve were seen in the $9 \mathrm{mg}, 16 \mathrm{mg}$, and $32 \mathrm{mg}$ albiglutide groups at days 2 and 9 . Postprandial glucose reductions were similar. ${ }^{15,16}$

\section{Efficacy and safety Phase I clinical trials}

Bush et al conducted a single-blind, randomized, placebocontrolled Phase I trial to assess the safety, tolerability, pharmacodynamics, and pharmacokinetics of escalating doses of albiglutide in healthy subjects (mean age 45.4 years, mean fasting plasma glucose $97.4 \mathrm{mg} / \mathrm{dL}$, mean body mass index $27.2 \mathrm{~kg} / \mathrm{m}^{2}, 59 \%$ male, $95 \%$ Hispanic/Latino). The groups received $0.25 \mathrm{mg}+1 \mathrm{mg}$ (cohort 1), $3 \mathrm{mg}+6 \mathrm{mg}$ (cohort 2), $16 \mathrm{mg}+24 \mathrm{mg}$ (cohort 3), $48 \mathrm{mg}+60 \mathrm{mg}$ (cohort 4), or $80 \mathrm{mg}+104 \mathrm{mg}$ (cohort 5). A dose-dependent trend in lowering of the weighted mean area under the curve for glucose occurred and was sustained over 24 hours. The adverse effects reported for the placebo and albiglutide groups were similar. Headache was the most common of the adverse effects deemed to be study drug-related. Constipation, nausea, and flatulence occurred in one subject each, and all at the lowest dose. No hypoglycemic events occurred in any of the subjects. Antibodies were not detected and no electrocardiographic changes were observed. ${ }^{12}$

\section{Phase II clinical trials}

Rosenstock et al investigated the safety, efficacy, and tolerability of escalating doses of albiglutide in patients with uncontrolled type 2 diabetes mellitus (baseline $\mathrm{HbA}_{1 \mathrm{C}}$ $7.9 \%-8.2 \%$, average duration of type 2 diabetes mellitus 3.9-6.4 years, see Table 1). Exenatide was included as an open-label clinical reference. There was a consistent trend of weight reduction observed across all doses of albiglutide (ranging from $-1.1 \mathrm{~kg}$ to $-1.7 \mathrm{~kg}$ ) but was less than in patients who received exenatide $(-2.4 \mathrm{~kg})$. The most frequently reported adverse effects were nausea $(12 \%-54 \%)$, vomiting $(8.6 \%-41 \%)$, diarrhea $(5.7 \%-22 \%)$, and headache (11.4\%-23.5\%). Gastrointestinal adverse effects were largely dose-dependent but declined over the course of the study. Injection site reactions were more common with albiglutide (28.6\%) than with placebo $(2.9 \%)$ and exenatide $(2.9 \%)$, but were mainly mild and unrelated to dose or frequency of administration. No serious episodes of hypoglycemia occurred. Anti-albiglutide antibodies were detected in eight patients; however, three of these patients had positive titers at baseline, suggesting that immunogenicity may be overestimated. Overall, albiglutide improved glucose control in a dose-dependent manner, with a higher frequency of gastrointestinal adverse effects in the monthly dosing groups. ${ }^{16}$

Seino et al compared the safety, pharmacokinetics, and pharmacodynamics of escalating doses of albiglutide in Japanese patients with uncontrolled type 2 diabetes mellitus. The patients were primarily male $(87.5 \%)$ and had a mean body mass index of $24.53 \mathrm{~kg} / \mathrm{m}^{2}$ (Table 1). Baseline characteristics were similar for all but the $30 \mathrm{mg}$ weekly group, which had a lower mean body weight at baseline. Forty patients were randomized to receive albiglutide $15 \mathrm{mg}$ or $30 \mathrm{mg}$ once weekly, $50 \mathrm{mg}$ biweekly, $100 \mathrm{mg}$ monthly, or placebo over a 4-week period. Weight changes with albiglutide ranged from $-0.8 \mathrm{~kg}$ to $+0.2 \mathrm{~kg}$, with the $50 \mathrm{mg}$ group experiencing the largest degree of weight loss. However, the placebo group also lost weight $(-0.3 \mathrm{~kg})$. Adverse effects were most common in the $100 \mathrm{mg}$ albiglutide group; flatulence (37.5\%, $\mathrm{n}=3)$, vomiting $(37.5 \%, \mathrm{n}=3)$, and nausea $(25 \%, \mathrm{n}=2)$ were reported most frequently in this group. Nausea, abdominal pain, diarrhea, and hypoglycemia were each reported once in the $15 \mathrm{mg}$ cohort, and one patient in the placebo group experienced flatulence. There was one report of injection site erythema in the $30 \mathrm{mg}$ group. The difference in injection site reactions between this study and the study by Rosenstock et al cannot readily be attributed to sample size and is therefore unknown. ${ }^{14,16}$ Anti-albiglutide antibodies were not detected in any treatment group. ${ }^{14}$ 
Table I Phase II clinical trials of albiglutide

\begin{tabular}{|c|c|c|c|c|c|c|}
\hline Study & Population & Duration & Treatment & $\begin{array}{l}\text { Change in } \\
\operatorname{HbA}_{\mathrm{Ic}}(\%)\end{array}$ & $\begin{array}{l}\text { Change in } \\
\text { FPG }(\mathrm{mg} / \mathrm{dL})\end{array}$ & $\begin{array}{l}\text { Change in } \\
\text { weight (kg) }\end{array}$ \\
\hline Seino et $\mathrm{al}^{17}$ & $\mathrm{n}=215$ & 16 weeks & Placebo & +0.27 & & -0.67 \\
\hline \multirow[t]{3}{*}{$\mathrm{R}, \mathrm{DB}, \mathrm{PC}, \mathrm{PG}, \mathrm{MC}, \mathrm{DR}$} & Japanese patients & & Albiglutide 15 mg weekly & -0.63 & & +0.40 \\
\hline & with T2DM & & Albiglutide 30 mg weekly & -1.29 & $-42.7 *$ & \\
\hline & & & Albiglutide $30 \mathrm{mg}$ biweekly & -0.84 & & \\
\hline Rosenstock et $\mathrm{al}^{16}$ & $\mathrm{n}=345$ & 16 weeks & Placebo & $-0.17 \pm 1.01$ & $-1.8 \pm 52.3$ & $-0.7 \pm 2.9$ \\
\hline \multirow[t]{9}{*}{$R, D B, P C, P G, M C, D R$} & Patients with & & Albiglutide 4 mg weekly & $-0.11 \pm 1.16$ & $-8.5 \pm 56.2$ & $-0.9 \pm 1.7$ \\
\hline & T2DM inadequately & & Albiglutide 15 mg weekly & $-0.49 \pm 0.74$ & $-13.0 \pm 30.3$ & $-0.9 \pm 2.9$ \\
\hline & controlled on & & Albiglutide 30 mg weekly & $-0.87 \pm 0.65^{*}$ & $-25.9 \pm 36.6 *$ & $-1.4 \pm 2.4$ \\
\hline & metformin or diet/ & & Albiglutide 15 mg biweekly & $-0.56 \pm 0.97$ & $-23.1 \pm 43.8$ & $-1.8 \pm 2.8$ \\
\hline & exercise & & Albiglutide $30 \mathrm{mg}$ biweekly & $-0.79 \pm 0.98$ & $-28.5 \pm 37.1 *$ & $-1.6 \pm 2.5$ \\
\hline & & & Albiglutide 50 mg biweekly & $-0.79 \pm 1.04 *$ & $-23.8 \pm 63.4^{*}$ & $-1.1 \pm 2.9$ \\
\hline & & & Albiglutide 50 mg monthly & $-0.55 \pm 1.01$ & $13.0 \pm 49.9$ & $-1.1 \pm 3.2$ \\
\hline & & & Albiglutide $100 \mathrm{mg}$ monthly & $-0.87 \pm 0.87 *$ & $22.0 \pm 63.1 *$ & $-1.7 \pm 3.6$ \\
\hline & & & Exenatide $5-10 \mu \mathrm{g}$ BID & $-0.54 \pm 0.91 *$ & $14.4 \pm 44.7$ & $-2.4 \pm 3.5$ \\
\hline Seino et $\mathrm{al}^{14}$ & $\mathrm{n}=40$ & 29 days & Placebo & -0.30 & $\mathrm{~N} / \mathrm{A}$ & N/A \\
\hline \multirow[t]{4}{*}{ R, SB, PC, PG, MC, DR } & Japanese patients & & Albiglutide 15 mg weekly & $-0.58 *$ & $-34.6 *$ & -2.86 \\
\hline & with T2DM & & Albiglutide 30 mg weekly & $-0.57 *$ & $-35.7 *$ & -3.58 \\
\hline & & & Albiglutide 50 mg biweekly & $-0.63 *$ & $-31.4 *$ & -2.51 \\
\hline & & & Albiglutide $100 \mathrm{mg}$ monthly & $-0.5 I *$ & -13.2 & -1.44 \\
\hline Matthews et al ${ }^{15}$ & $\mathrm{n}=54$ & 9 days & Placebo & N/A & N/A & $\mathrm{N} / \mathrm{A}$ \\
\hline \multirow[t]{3}{*}{$R, S B, P C, P G, D R$} & Patients with & & Albiglutide 9 mg weekly & $\mathrm{N} / \mathrm{A}$ & $-23.8^{*}$ & $\mathrm{~N} / \mathrm{A}$ \\
\hline & T2DM & & Albiglutide 16 mg weekly & $N / A$ & $-32.5^{*}$ & N/A \\
\hline & & & Albiglutide 32 mg weekly & $N / A$ & $-50.7^{*}$ & $\mathrm{~N} / \mathrm{A}$ \\
\hline
\end{tabular}

Note: $* P<0.05$ compared with placebo. Figures are presented as mean \pm standard deviation.

Abbreviations: $\mathrm{HbA}_{1 \mathrm{c}}$, glycated hemoglobin; BID, twice daily; DB, double-blind; DR, dose-ranging; FPG, fasting plasma glucose; MC, multicenter; N/A, not applicable; PC, placebo-controlled; PG, parallel-group; R, randomized; SB, single-blind; T2DM, type 2 diabetes mellitus.

A more recently published Phase IIb study by Seino et al compared the safety and efficacy of albiglutide $15 \mathrm{mg}$ weekly, $30 \mathrm{mg}$ weekly, and $30 \mathrm{mg}$ biweekly versus placebo in 215 Japanese patients with type 2 diabetes mellitus (Table 1). The primary end point was change in $\mathrm{HbA}_{1 \mathrm{C}}$ at week 16 . All doses of albiglutide resulted in a statistically significant decrease in $\mathrm{HbA}_{1 \mathrm{C}}$ when compared with placebo; the largest decrease was observed in the $30 \mathrm{mg}$ weekly group $(-1.55 \%$, $P<0.001$ ). In the $30 \mathrm{mg}$ weekly group, $63.0 \%$ of patients achieved an $\mathrm{HbA}_{1 \mathrm{C}}<7.4 \%$ by week 16 compared with $6.0 \%$ in the placebo group. The mean change in body weight was $<1 \mathrm{~kg}$ for all treatment groups and was not statistically significant. The most common adverse effects in the treatment groups were nasopharyngitis, injection site reactions, and diarrhea, which were all comparable with placebo. Other gastrointestinal adverse effects were comparable with placebo and occurred at less frequent rates than in the study by Rosenstock et al. ${ }^{16}$

Matthews et al investigated the pharmacodynamics, pharmacokinetics, safety, and tolerability of albiglutide in patients with type 2 diabetes mellitus taking metformin and sulfonylureas, either alone or in combination (Table 1). Two separate studies were performed, ie, a dose-escalation and an injection site study. After a 2-week washout of prior oral antihyperglycemic medications, 54 patients were randomized to receive placebo or albiglutide $9 \mathrm{mg}$, $16 \mathrm{mg}$, or $32 \mathrm{mg}$ on days 1 and 8. Fasting and postprandial plasma glucose reductions at all time points were similar between the albiglutide groups. In the injection site study, 46 patients were randomized to receive a single dose of $16 \mathrm{mg}$ or $64 \mathrm{mg}$ of albiglutide injected into the arm, leg, or abdomen. The most common adverse events over the 9-day treatment course were headache and nausea, rates of which were comparable between the placebo and treatment groups and not dose-dependent. No hypoglycemic episodes or electrocardiographic abnormalities were reported in the albiglutide groups. ${ }^{15}$

\section{Phase III clinical trials}

Based on the efficacy, safety, and tolerability of albiglutide doses in the Phase I and II trials, albiglutide $30 \mathrm{mg}$ and $50 \mathrm{mg}$ once weekly were evaluated in eight Phase III trials, collectively known as the Harmony program. This program investigated the efficacy, tolerability, and safety of albiglutide as monotherapy or as add-on therapy in approximately 5,000 patients with type 2 diabetes mellitus. 
Harmony 1 evaluated the safety and efficacy of albiglutide as add-on therapy in patients inadequately controlled on pioglitazone with or without metformin (Table 2). Patients were randomized to receive either albiglutide $30 \mathrm{mg}$ subcutaneously once weekly or placebo in addition to their baseline regimen of pioglitazone with or without metformin. Patients reaching predefined $\mathrm{HbA}_{1 \mathrm{C}}$ thresholds were started on hyperglycemic rescue therapy but remained on blinded treatment during the trial. At week 52, both $\mathrm{HbA}_{1 \mathrm{C}}$ and fasting plasma glucose were significantly decreased relative to baseline in those receiving albiglutide compared with placebo (both $P<0.001$ ). Forty-four percent of patients receiving albiglutide achieved an $\mathrm{HbA}_{1 \mathrm{C}}<7 \%$ compared with only $15 \%$ of those receiving placebo. ${ }^{18}$

Hyperglycemic rescue was used in $40.9 \%$ of patients in the placebo group but in only $22.7 \%$ of the albiglutide group (with insulin as rescue therapy in $21.2 \%$ and $10 \%$, respectively). Both groups experienced a similar change in weight from baseline. Treatment was discontinued due to adverse events in $3.2 \%$ of the albiglutide group and in $6.3 \%$ in the placebo group. Rates of nausea and vomiting were similar between albiglutide $(10.7 \%, 4.0 \%)$ and placebo $(11.3 \%$, $4.0 \%$ ) while rates of diarrhea ( $11.3 \%$ versus $8.6 \%)$ and injection site reactions ( $11.3 \%$ versus $7.9 \%$ ) were slightly higher in those receiving albiglutide. The incidence of documented symptomatic hypoglycemia (blood glucose $\leq 70 \mathrm{mg} / \mathrm{dL}$ ) was $3 \%$ for albiglutide (versus $1 \%$ for placebo). The rate of severe hypoglycemia in the albiglutide arm was $1 \% .{ }^{18}$ This study demonstrated the clinical efficacy and tolerability of albiglutide as add-on therapy for patients who are uncontrolled on pioglitazone with or without metformin.

Harmony 2 examined the safety and efficacy of albiglutide monotherapy versus placebo in drug-naïve patients with type 2 diabetes mellitus (Table 2). Patients were randomized to receive either albiglutide $30 \mathrm{mg}$ or $50 \mathrm{mg}$ or placebo subcutaneously once weekly. Those in the albiglutide $50 \mathrm{mg}$ group were started on $30 \mathrm{mg}$ and increased to $50 \mathrm{mg}$ at week 12 . Patients were allowed to continue in the study if hyperglycemic rescue was required. At week $52, \mathrm{HbA}_{1 \mathrm{C}}$ and fasting plasma glucose levels were significantly decreased relative to baseline for both albiglutide $30 \mathrm{mg}$ and $50 \mathrm{mg}$ compared with placebo. A target $\mathrm{HbA}_{1 \mathrm{C}}$ of $<7 \%$ was achieved in $49.0 \%$ of the albiglutide $30 \mathrm{mg}$ group, $40.9 \%$ of the albiglutide $50 \mathrm{mg}$ group, and in none of the patients in the placebo group. Hyperglycemic rescue was required in $50 \%$ of those in the placebo group, $20 \%$ in the albiglutide $30 \mathrm{mg}$ group, and $16 \%$ in the albiglutide $50 \mathrm{mg}$ group. Metformin was preferentially recommended for hyperglycemic rescue. A similar decrease in weight was reported in all groups. Treatment was discontinued due to adverse events in $2 \%$ of the placebo group, $5 \%$ of the $30 \mathrm{mg}$ group, and $13 \%$ of the $50 \mathrm{mg}$ group. The most common adverse effects were gastrointestinal and similar between groups. Injection site reactions were higher in the two albiglutide arms (10\% placebo, $18 \%$ albiglutide $30 \mathrm{mg}, 22 \%$ albiglutide $50 \mathrm{mg}$ ) but most were mild in nature. There were no reports of severe hypoglycemia, acute pancreatitis, or thyroid cancer in the albiglutide groups. ${ }^{19}$ Harmony 2 demonstrated the clinical efficacy of the $30 \mathrm{mg}$ and $50 \mathrm{mg}$ doses of albiglutide, with similar rates of gastrointestinal adverse events occurring in all groups. Albiglutide was also shown to be a safe option for monotherapy in drugnaïve patients with type 2 diabetes mellitus.

Harmony 3 compared the efficacy and safety of albiglutide with that of sitagliptin, glimepiride, and placebo when added to baseline metformin therapy (Table 2). Two run-in treatments were started in all patients, ie, metformin (uptitrated to a maximum tolerated dosage over 2 weeks) and a diet and exercise regimen (1 week prior to randomization). Patients were then randomized to receive either albiglutide $30 \mathrm{mg}$ weekly, sitagliptin $100 \mathrm{mg}$ orally once daily, glimepiride $2 \mathrm{mg}$ to $4 \mathrm{mg}$ orally once daily, or a weekly placebo injection. Patients reaching predefined hyperglycemic thresholds qualified for blinded dose titration (albiglutide $30 \mathrm{mg}$ to $50 \mathrm{mg}$ and glimepiride $2 \mathrm{mg}$ to $4 \mathrm{mg}$ ). At week 104, the mean $\mathrm{HbA}_{1 \mathrm{C}}$ increased in the placebo group and decreased in all treatment groups compared with baseline. However, the albiglutide group had a significantly greater reduction in $\mathrm{HbA}_{1 \mathrm{C}}$ compared with the sitagliptin and glimepiride groups. The albiglutide group also had a significantly greater reduction in fasting plasma glucose when compared with placebo, sitagliptin, and glimepiride. Hyperglycemic rescue with insulin therapy was initiated at an $\mathrm{HbA}_{1 \mathrm{C}}$ of $8.5 \%$ and occurred in the albiglutide, glimepiride, sitagliptin, and placebo groups in $26 \%, 33 \%, 36 \%$, and $59 \%$ of patients, respectively. Weight loss was similar in the placebo, albiglutide, and sitagliptin groups but increased in the glimepiride group. Treatment was discontinued due to adverse events at similar rates across the treatment arms. Common adverse events attributed to placebo, sitagliptin, glimepiride, and albiglutide included nausea $(11 \%, 7 \%, 6 \%$, and $10 \%$, respectively), vomiting $(1 \%, 4 \%, 4 \%$, and $6 \%$, diarrhea $(11 \%, 9 \%, 9 \%$, and $13 \%)$, and upper respiratory tract infection $(10 \%, 9 \%, 9 \%$, and $16 \%)$. However, the prevalence of nausea or vomiting in albiglutide-treated patients declined by week 8 of treatment to a rate similar to that in the sitagliptin and placebo groups, but less than that in the 


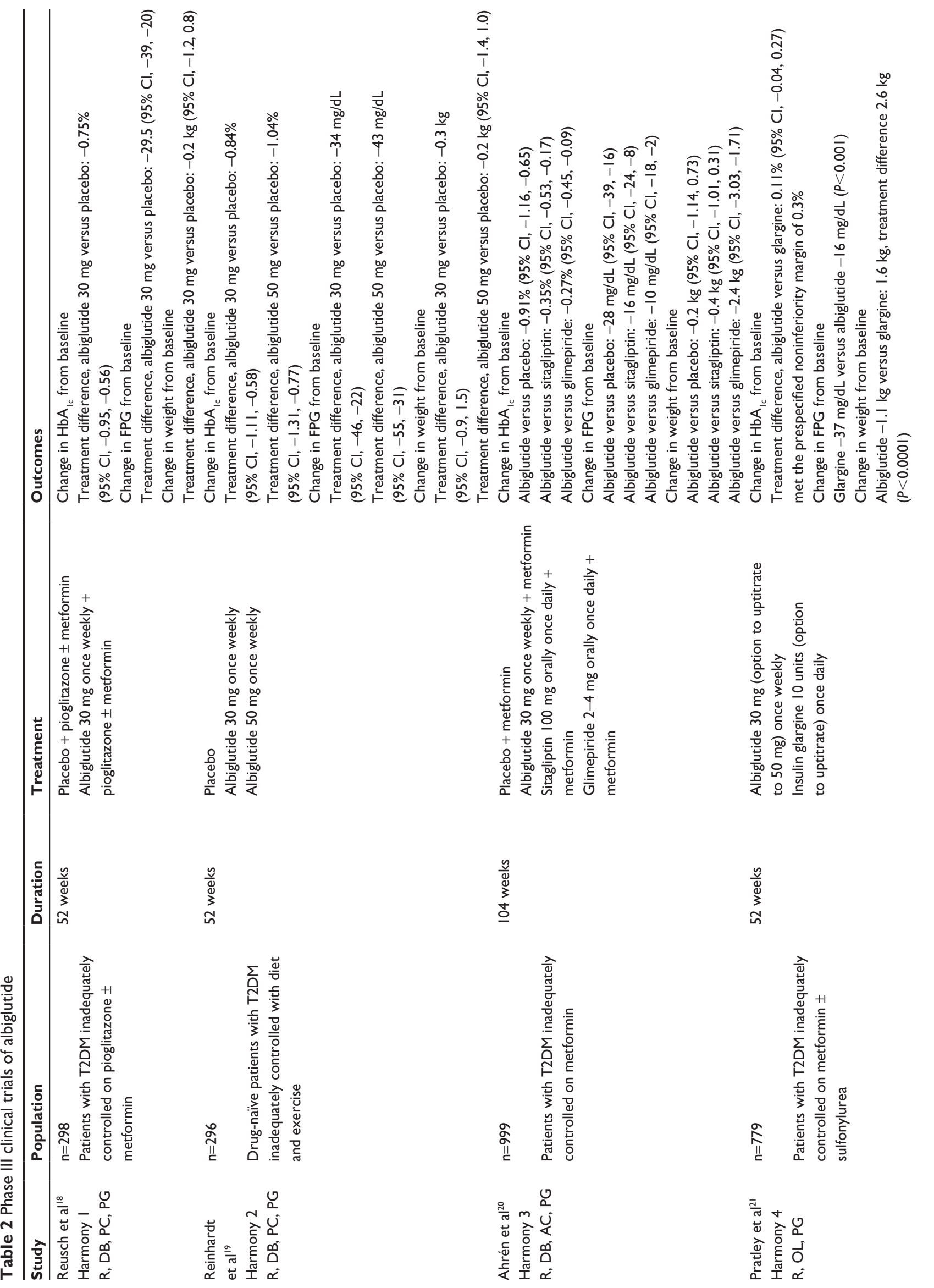




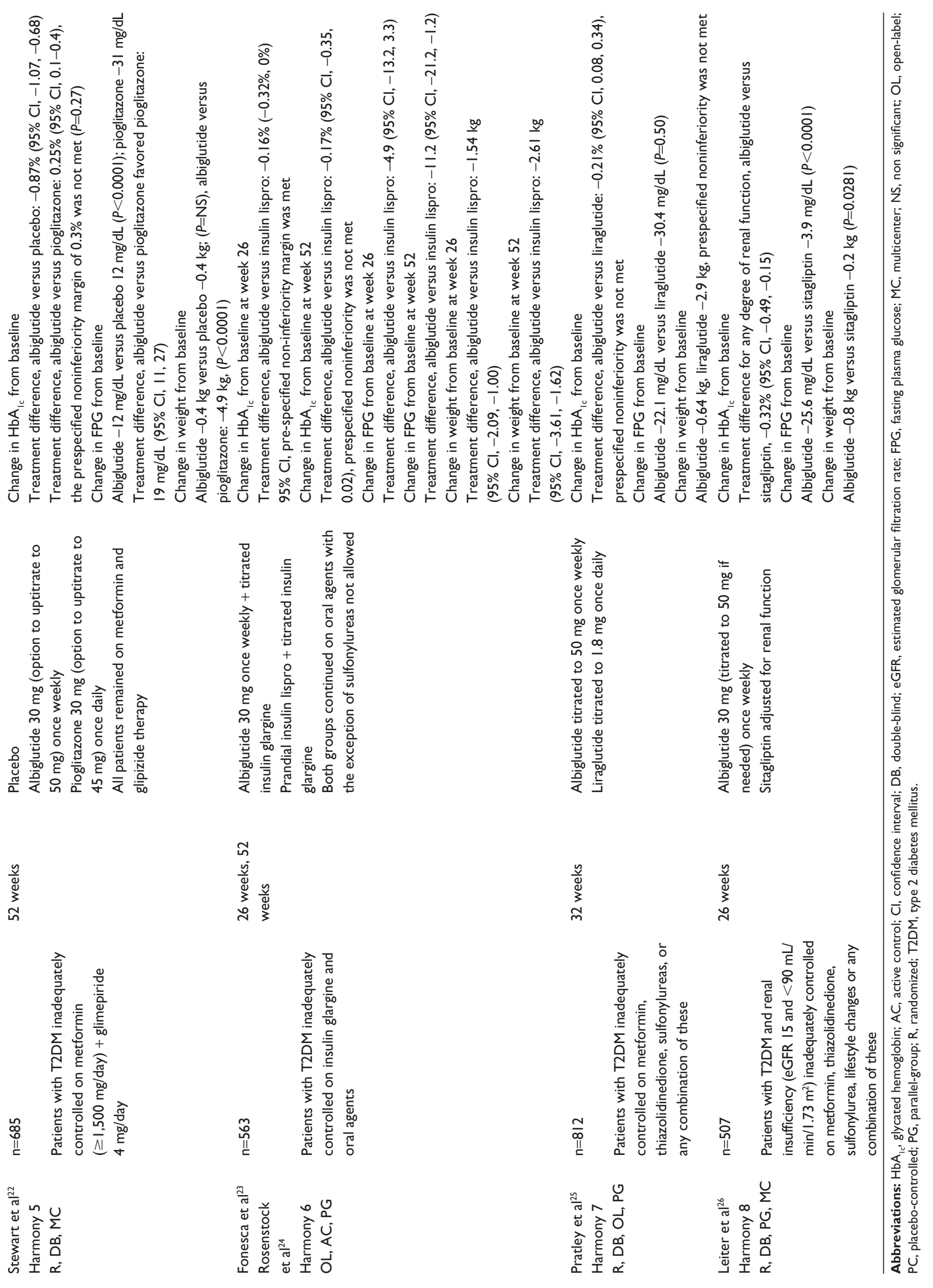


glimepiride group. Injection site reactions in the albiglutide group were mostly mild or moderate in nature (17\%). The incidence of documented symptomatic hypoglycemic (blood glucose $\leq 70 \mathrm{mg} / \mathrm{dL}$ ) events (prior to addition of hyperglycemia rescue medication) was $4 \%$ with placebo, $2 \%$ with sitagliptin, $18 \%$ with glimepiride, and $3 \%$ with albiglutide. Two patients on albiglutide had probable pancreatitis that was possibly related to their treatment, and one patient developed thyroid cancer. ${ }^{20}$ Results from Harmony 3 demonstrated that albiglutide lowered $\mathrm{HbA}_{1 \mathrm{C}}$ to a greater degree than glimepiride and sitagliptin, with gastrointestinal adverse effects attenuating by around week 8 of treatment. This was also the first trial in the Harmony series to raise concerns about the debated class effect of pancreatitis and thyroid cancer.

Harmony 4 compared the safety and efficacy of albiglutide $30 \mathrm{mg}$ once weekly with that of insulin glargine when added to metformin and/or a sulfonylurea in patients with type 2 diabetes mellitus (Table 2). Patients were randomized to receive albiglutide $30 \mathrm{mg}$ once weekly (titrated to $50 \mathrm{mg}$ weekly if needed) or insulin glargine daily (titrated individually if needed) to a target $\mathrm{HbA}_{1 \mathrm{C}} \leq 7.0 \%$ and a fasting plasma glucose $\leq 100 \mathrm{mg} / \mathrm{dL}$. Eighty-two percent of patients continued baseline metformin and a sulfonylurea. By week $47,39.1 \%$ of patients treated with albiglutide had been uptitrated to $50 \mathrm{mg}$. Insulin glargine was started at a median dose of 10 (range 2-40) units and increased to a median of 30 (range 3-152) units by week 52. At week 52, a goal $\mathrm{HbA}_{1 \mathrm{C}}$ of $<7 \%$ was reached at similar rates in the albiglutide $(32 \%)$ and insulin glargine (33\%) groups. Reduction from baseline $\mathrm{HbA}_{1 \mathrm{C}}$ was also similar between albiglutide $(-0.67 \%)$ and insulin glargine $(-0.79 \%)$, with a treatment difference that met the prespecified criterion for declaring noninferiority of albiglutide to insulin glargine. There was a significant difference in fasting plasma glucose in favor of insulin glargine compared with albiglutide. Those in the albiglutide group lost weight, while those on insulin glargine gained weight. ${ }^{21}$

Common adverse events that occurred at similar rates in the albiglutide and insulin glargine groups were vomiting (3.8\% versus $3.7 \%$ ) and upper respiratory tract infection ( $9 \%$ versus $10 \%$ ). Nausea and diarrhea were more prevalent in the albiglutide group (9.9\% and $7.5 \%$, respectively) when compared with the insulin glargine group $(4.1 \%$ and $3.7 \%$ ). Injection site reactions were also more common in the albiglutide group than in the glargine group (13.9\% versus $8.7 \%$, respectively). Documented symptomatic hypoglycemia (blood glucose $\leq 70 \mathrm{mg} / \mathrm{dL}$ ) occurred less often in the albiglutide group (21\%) than in the insulin glargine group $(29 \%)$, and was associated with concurrent sulfonylurea use. Severe hypoglycemic events were similar between the groups (both $0.4 \%$ ). Two patients in the albiglutide group and one patient in the insulin glargine group developed pancreatitis during the study. An independent blinded pancreatitis adjudication committee identified one patient in the albiglutide group as having probable pancreatitis that was at least possibly related to the study drug. No patients developed thyroid cancer. ${ }^{21}$ Harmony 4 demonstrated that there was no statistically significant difference between albiglutide and insulin glargine with regard to reduction in $\mathrm{HbA}_{1 \mathrm{C}}$ after 52 weeks of therapy $(P=0.15)$. Nausea, diarrhea, and injection site reactions occurred more frequently in the albiglutide group, while vomiting and upper respiratory tract infection occurred at similar rates between the groups. Most adverse events were mild to moderate in intensity.

Harmony 5 compared the efficacy and safety of albiglutide weekly with that of pioglitazone when added to a baseline regimen of metformin and glimepiride (Table 2). Patients were randomized to albiglutide $30 \mathrm{mg}$ once weekly, pioglitazone $30 \mathrm{mg}$ once daily, or placebo. Baseline metformin and glimepiride regimens were continued. Albiglutide was increased from $30 \mathrm{mg}$ to $50 \mathrm{mg}$ once weekly and pioglitazone from $30 \mathrm{mg}$ to $45 \mathrm{mg}$ daily at weeks 4 and 12 if fasting plasma glucose was $>250 \mathrm{mg} / \mathrm{dL}$ and thereafter if $\mathrm{HbA}_{1 \mathrm{C}}$ was $>7 \%$. Patients were allowed to continue if hyperglycemic rescue was required. Uptitration occurred in $70.1 \%$ of patients in the albiglutide group and in $54.9 \%$ of patients in the pioglitazone group. At week 52, the mean reduction in $\mathrm{HbA}_{1 \mathrm{C}}$ in the albiglutide group was statistically significant versus the placebo group, but noninferiority was not achieved versus pioglitazone. The percentage of patients achieving an $\mathrm{HbA}_{1 \mathrm{C}}$ goal $<7 \%$ was slightly higher for pioglitazone (35\%) than for albiglutide $(30 \%)$, but both were higher than placebo (9\%). The pioglitazone group also had a significantly greater decrease in fasting plasma glucose versus the albiglutide group. The albiglutide and placebo groups experienced a mean weight loss, while the pioglitazone group experienced weight gain. More patients in the pioglitazone and placebo groups withdrew from the study due to adverse events $(6.9 \%$ and $5.2 \%$, respectively) when compared with the albiglutide group (4.4\%). Gastrointestinal adverse events were experienced less frequently in the placebo and pioglitazone groups than in the albiglutide group, and comprised nausea (3.5\%, 4.3\%, and $9.6 \%$, respectively), diarrhea $(2.6 \%, 5.4 \%$, and $8.9 \%)$, and vomiting $(0.9 \%, 1.8 \%$, and $2.6 \%)$. Injection site reactions were also more common in the albiglutide group (12.9\%) than in the placebo $(3.5 \%)$ and pioglitazone $(3.2 \%)$ groups, but the majority of reactions were mild. The rate of severe hypoglycemia in the albiglutide group was $0.4 \%$ and higher 
in the pioglitazone group at $1.1 \%$. Four patients in total (three in the albiglutide group and one in the placebo group) were evaluated for pancreatitis. Two patients in the albiglutide arm of the study were identified as having probable pancreatitis that was possibly related to the study drug. ${ }^{22}$ This study demonstrated that, when added to baseline metformin and glimepiride, albiglutide significantly decreased $\mathrm{HbA}_{1 \mathrm{C}}$ at week 52 relative to placebo but did not meet the criteria for noninferiority when compared with pioglitazone. Gastrointestinal and injection site adverse events were more common with albiglutide but were generally mild in nature.

Harmony 6 compared once-weekly albiglutide versus prandial insulin lispro, both combined with titrated insulin glargine (Table 2). After an initial run-in period with insulin glargine, patients were randomized to receive albiglutide $30 \mathrm{mg}$ once weekly or meal-time insulin lispro and continued on home metformin and/or thiazolidinedione therapy. Both groups also received insulin glargine titrated to target a fasting plasma glucose of $80-130 \mathrm{mg} / \mathrm{dL}$. Insulin lispro was adjusted as per the prespecified algorithm based on blood glucose monitoring, and albiglutide could be uptitrated to $50 \mathrm{mg}$ once weekly based on progressively lower $\mathrm{HbA}_{1 \mathrm{C}}$ targets. Hyperglycemia rescue was permitted in both treatment arms based on $\mathrm{HbA}_{1 \mathrm{C}}$ thresholds. At 26 weeks, both groups experienced a reduction in $\mathrm{HbA}_{1 \mathrm{C}}$ from baseline (albiglutide $-0.82 \% \pm 0.06 \%$ and insulin lispro $-0.66 \% \pm 0.06 \%$ ), with a treatment difference that met prespecified noninferiority, with a trend toward superiority $(P=0.053)$. At 52 weeks, both groups experienced a further decrease in $\mathrm{HbA}_{1 \mathrm{C}}$, but at this time point, albiglutide did not meet noninferiority versus insulin lispro $(-1.01 \% \pm 0.07 \%$ and $-0.84 \% \pm 0.06 \%$, respectively; $P=0.086$ ). At week 26 , there were similar decreases in fasting plasma glucose with albiglutide and insulin lispro $(-18 \mathrm{mg} / \mathrm{dL}$ and $-13 \mathrm{mg} / \mathrm{dL}$, respectively; $P=0.236$ ), but these were significantly lower by week 52 with albiglutide versus lispro $(-27 \mathrm{mg} / \mathrm{dL}$ and $-16 \mathrm{mg} / \mathrm{dL}$, respectively; $P=0.028)$. At week 52 , the target $\mathrm{HbA}_{1 \mathrm{C}}$ level of $<7.0 \%$ was reached in $45 \%$ of those receiving albiglutide versus $30 \%$ of those receiving insulin lispro ( $P=0.231$ for treatment difference). The average dose of glargine was similar between the albiglutide and insulin lispro groups and a similar percentage of patients in each group required hyperglycemic rescue $(43.5 \%$ and $38.8 \%$, respectively, at week $52, P=0.326) .{ }^{23,24}$

Throughout the study, patients on albiglutide lost weight while those on insulin lispro gained weight $(-0.96 \mathrm{~kg}$ and $+1.66 \mathrm{~kg}$, respectively; $P<0.001$ ). Interestingly, 158 patients in the albiglutide arm and 137 patients in the insulin lispro arm failed to complete the study; the reason for this is unknown.
Adverse events were more common in the albiglutide group than in the insulin lispro group, with nausea (13\% versus $2 \%$ ), diarrhea ( $14 \%$ versus $6 \%$ ), and injection site reactions (10\% versus $5 \%$ ) being the most common. Hypoglycemia (blood glucose $\leq 70 \mathrm{mg} / \mathrm{dL}$ ) was reported in $23 \%$ of those receiving albiglutide compared with $39 \%$ of those receiving insulin lispro. No severe hypoglycemic events were reported for albiglutide ( $1 \%$ for lispro). ${ }^{23,24}$ Harmony 6 demonstrated that albiglutide produced clinically relevant reductions in $\mathrm{HbA}_{1 \mathrm{C}}$ that were comparable with those achieved on insulin lispro, with less hypoglycemia and slightly higher rates of gastrointestinal adverse events.

Harmony 7 was a noninferiority trial that compared albiglutide $50 \mathrm{mg}$ once weekly with liraglutide $1.8 \mathrm{mg}$ once daily in patients with type 2 diabetes mellitus (Table 2). After a 4 week run-in period, patients were randomized to receive either albiglutide $30 \mathrm{mg}$ once weekly (titrated up to $50 \mathrm{mg}$ once weekly at week 6), or liraglutide $0.6 \mathrm{mg}$ daily (titrated to $1.8 \mathrm{mg}$ daily at week 3 ). Patients who had predefined hyperglycemia could begin rescue treatment after week 2 , with insulin as the preferred add-on agent. At week 32, albiglutide demonstrated less glycemic efficacy when compared with liraglutide. Baseline $\mathrm{HbA}_{1 \mathrm{C}}$ changed by $-0.78 \% \pm 0.99 \%$ with albiglutide and $-0.99 \% \pm 1.02 \%$ with liraglutide, but the treatment difference did not meet the noninferiority criterion $(P=0.085){ }^{25}$

The treatment goals of $\mathrm{HbA}_{1 \mathrm{C}}<7 \%$ and $<6.5 \%$ were met in a significantly greater percentage of those receiving liraglutide versus those receiving albiglutide (52\% and $28 \%$ versus $42 \%$ and $20 \% ; P=0.002$ and $P=0.001$, respectively). Changes in fasting plasma glucose from baseline mirrored changes in $\mathrm{HbA}_{1 \mathrm{C}}$ and were significantly lower in the liraglutide group versus the albiglutide group. By week 32, hyperglycemic rescue occurred in a higher percentage of those in the albiglutide group (15\%) versus the liraglutide group (8\%), and the time to hyperglycemic rescue was longer for the liraglutide group $(P=0.005)$. Weight significantly decreased from baseline in both groups but the decrease was significantly greater with liraglutide. Gastrointestinal adverse events were common in both groups, but occurred more often in the liraglutide group than in the albiglutide group (49.0\% versus $35.9 \% ; P=0.001)$. Study withdrawal due to gastrointestinal adverse events was also more common in the liraglutide group (6.4\%) than in the albiglutide group $(2.5 \%)$. The most common adverse events were diarrhea, upper respiratory tract infection, nausea, vomiting, and injection site reactions. Diarrhea occurred at similar rates between the groups (albiglutide 14.9\%, liraglutide 13.5\%; $P=0.575$ ) as did upper respiratory tract infection (albiglutide 
$10.4 \%$, liraglutide $11 \% ; P=0.771)$. However, nausea was significantly more common with liraglutide (29.2\%) than with albiglutide $(9.9 \% ; P<0.001)$, as was vomiting (albiglutide $5 \%$ versus liraglutide $9.3 \% ; P=0.015$ ). Injection site reactions were significantly more common with albiglutide than with liraglutide $(6.9 \%$ versus $1.2 \% ; P<0.001)$. Symptomatic hypoglycemia occurred in $16.3 \%$ of those receiving albiglutide and in $20.8 \%$ of those receiving liraglutide. Most of these hypoglycemic events occurred with concomitant sulfonylurea use. There were no documented cases of severe hypoglycemia. One person in the albiglutide group and two in the liraglutide group were determined to have probable or definite pancreatitis that was possibly related to treatment. ${ }^{25}$ This head-to-head trial of GLP-1 receptor agonists demonstrated that albiglutide was less clinically efficacious than liraglutide but was associated with significantly less nausea and vomiting. Discontinuation of therapy due to gastrointestinal adverse events was more common in the liraglutide group, which may have implications for patient adherence. Hypoglycemic episodes were more common in the liraglutide group than in the albiglutide group, and were most common with concurrent sulfonylureas. This finding, along with the higher rate of hypoglycemia in the sulfonylurea arm of the Harmony 3 trial, may limit the concurrent use of sulfonylureas with GLP-1 receptor agonists..$^{20,25}$

Harmony 8 compared albiglutide $30 \mathrm{mg}$ once weekly with sitagliptin daily in patients with type 2 diabetes mellitus and any degree of renal impairment (mild, moderate, severe; estimated glomerular filtration rate $\geq 15$ and $<90 \mathrm{~mL} / \mathrm{min} / 1.73 \mathrm{~m}^{2}$, see Table 2). Patients were randomized to receive albiglutide (30 $\mathrm{mg}$ weekly, titrated to $50 \mathrm{mg}$ weekly based on glycemic response) plus placebo or sitagliptin (25 mg to $100 \mathrm{mg}$, depending on degree of renal impairment) plus placebo. The degree of renal impairment was similar between the groups. At 26 weeks, patients on albiglutide showed a clinically and statistically significant reduction in $\mathrm{HbA}_{1 \mathrm{C}}$ from baseline for any degree of renal impairment $(-0.83 \%)$ compared with sitagliptin $(-0.52 \%)$, with a treatment difference achieving not only noninferiority but also superiority $(P=0.003)$ in favor of albiglutide. A goal $\mathrm{HbA}_{1 \mathrm{C}}$ of $<7 \%$ was achieved by $42.6 \%$ in the albiglutide group and by $30.5 \%$ in the sitagliptin group. Fasting plasma glucose was also significantly decreased in the albiglutide group versus the sitagliptin group. ${ }^{26}$

Weight loss was significantly greater in the albiglutide group versus sitagliptin. The most common adverse events were nausea (albiglutide 4.8\%, sitagliptin 3.3\%), diarrhea (albiglutide $8.8 \%$, sitagliptin 6.1\%), and vomiting (albiglutide 1.6\%, sitagliptin 1.2\%). Documented hypoglycemia (blood glucose $<70 \mathrm{mg} / \mathrm{dL}$ ) prior to rescue medications occurred in $10.4 \%$ of the albiglutide group $(0 \%$ severe) and in $5.7 \%$ of the sitagliptin group ( $0.8 \%$ severe). Injection site reactions occurred in $6.8 \%$ of the albiglutide group and in $2.8 \%$ of the sitagliptin group. ${ }^{26}$ Harmony 8 is the only trial in the Harmony program to explore the efficacy and safety of albiglutide in those with any degree of renal impairment. Albiglutide demonstrated superior clinical efficacy compared with sitagliptin, with similar to slightly higher rates of gastrointestinal adverse events and less hypoglycemia. This is an important finding given that many patients with type 2 diabetes mellitus have concomitant renal impairment.

\section{Summary of Phase III trials}

The Harmony program assessed the efficacy, safety, and tolerability of once-weekly albiglutide in patients with type 2 diabetes mellitus who were previously uncontrolled with various combinations of oral antihyperglycemic agents, insulin, and/or diet and exercise. Baseline patients characteristics were similar in each trial. Baseline $\mathrm{HbA}_{1 \mathrm{C}}$ ranged from $8.1 \%$ to $8.5 \%$, patients had a mean duration of type 2 diabetes mellitus of 4-9 years, were aged 53-63 years, and approximately $40 \%-52 \%$ were female. ${ }^{18-26}$

Albiglutide demonstrated greater efficacy in lowering $\mathrm{HbA}_{1 \mathrm{C}}$ as add-on therapy to metformin when compared with glimepiride and sitagliptin. Significant $\mathrm{HbA}_{1 \mathrm{C}}$ and fasting plasma glucose reductions were also achieved when albiglutide was added to various combinations of pioglitazone, glimepiride, and metformin. Importantly, albiglutide was found to be noninferior to insulin glargine and at week 26 of 52 when compared with mealtime insulin lispro. Superiority of albiglutide over sitagliptin was achieved in a noninferiority trial in patients with renal impairment. However, albiglutide failed to achieve noninferiority when compared head-to-head with pioglitazone and liraglutide. Weight loss was moderate across the studies, and the class effect of gastrointestinal side effects was evident, although less common than with liraglutide. ${ }^{18-26}$ These findings may direct the use of albiglutide to those who need an additional reduction in $\mathrm{HbA}_{1 \mathrm{C}}$ and desire moderate weight loss, but are unable to tolerate other GLP-1 receptor agonists. The data from the Harmony series should confirm for practitioners and patients that this is an effective therapeutic option for type 2 diabetes mellitus.

\section{Dosage and administration}

GlaxoSmithKline recently approved once-weekly subcutaneous albiglutide $30 \mathrm{mg}$ and $50 \mathrm{mg}$ in the USA. ${ }^{4}$ Although it is an injectable agent, its once-weekly administration 
may be appealing to patients and may increase adherence over a product that is dosed once or multiple times per day. ${ }^{11}$

\section{Precautions and contraindications}

The safety of albiglutide in patients with renal impairment (estimated glomerular filtration rate $\geq 15$ and $<90 \mathrm{~mL} / \mathrm{min} /$ $1.73 \mathrm{~m}^{2}$ ) was studied in the Harmony 8 trial. Albiglutide was found to be both efficacious and safe in this population, with diarrhea and nausea being the most common side effects. ${ }^{26}$ More data are necessary to confirm these findings, but these initial data demonstrate albiglutide to be an effective therapy in patients with renal impairment.

As a class, GLP-1 receptor agonists have been implicated in case and post-marketing reports as being associated with an increased risk of pancreatitis, pancreatic cancer, and thyroid cancer. ${ }^{27}$ The reported incidence of pancreatitis in patients using the GLP-1 receptor agonist exenatide ranges from 0.33 to 5.7 cases per 1,000 patient years. ${ }^{28,29}$ The rates of necrotizing or hemorrhagic pancreatitis in exenatide users is much smaller at less than one in 10,000, which is similar to the rates in all patients with diabetes. ${ }^{30}$ GLP-1 receptor agonists have been associated with an increased risk of pancreatic cancer, but both the US Food and Drug Administration and the European Medicines Agency have concluded that there is insufficient evidence to suggest a causal relationship. ${ }^{31,32}$ Animal studies of both liraglutide and exenatide once weekly demonstrated an association with use of each agent and the development of thyroid C-cell tumors; however, this association has not been found in human data. ${ }^{33}$

Based on these concerns regarding pancreatitis, pancreatic cancer, and thyroid cancer, it is recommended to avoid the use of exenatide in patients with a history of pancreatitis and to avoid the use of exenatide once weekly and liraglutide in patients with a personal or family history of medullary thyroid cancer or multiple endocrine neoplasia $2 \mathrm{~A}$ or $2 \mathrm{~B} .{ }^{10,12,34}$ The albiglutide prescribing information has a black-box warning in line with those of exenatide once weekly and liraglutide. ${ }^{35}$

To date, there have been no notable cardiovascular adverse events attributed to albiglutide. One recently published, randomized, double-blind, single-center, parallel, nested Phase I cross-over study in healthy adults concluded that albiglutide does not prolong the QTc interval. ${ }^{36}$ The US Food and Drug Administration has requested post-marketing studies on cardiovascular outcomes in patients with a "high baseline risk of cardiovascular disease" and these data remain to be seen. ${ }^{4}$

\section{Adverse effects}

Like other GLP-1 receptor agonists, gastrointestinal adverse effects are those most commonly encountered with use of once-weekly albiglutide. Other common side effects include headache, dizziness, and upper respiratory tract infection. In the largest published albiglutide study to date (albiglutide $\mathrm{n}=404$ ), the most common side effects associated with albiglutide were diarrhea (14.9\%), upper respiratory tract infection $(10.4 \%)$, nausea $(9.9 \%)$, injection site reaction $(6.9 \%)$, urinary tract infection $(6.2 \%)$, nasopharyngitis $(5.9 \%)$, headache $(5.4 \%)$, and vomiting $(5.0 \%) .{ }^{25}$ One subject in the albiglutide group was determined by the pancreatitis adjudication committee to have probable or definite pancreatitis that was at least possibly related to GLP-1 receptor agonist therapy. No cases of thyroid cancer were diagnosed during the trial. ${ }^{25}$ Once-weekly dosing of albiglutide minimizes the side effects seen with larger doses administered at longer intervals. A complete list of adverse effects reported in the published Phase II and III albiglutide clinical trials can be found in Table $3 .{ }^{14-17,25}$

\section{Drug interactions}

The pharmacokinetic effects of albiglutide on warfarin, digoxin, and a low-dose oral contraceptive have been studied. ${ }^{37}$ Although albiglutide was not anticipated to cause cytochrome P450-mediated interactions, the delayed gastric emptying of albiglutide was hypothesized to potentially alter the oral absorption of the concurrently administered agents. ${ }^{37}$ However, the effect of long-acting GLP-1 receptor agonists on gastric emptying decreases rapidly with time, owing to their continuous activation of the GLP-1 receptor, probably due to receptor desensitization. ${ }^{38}$

\section{Warfarin}

Healthy subjects $(n=30)$ were administered a single dose of warfarin $25 \mathrm{mg}$ orally alone (day 1) and after steady-state albiglutide exposure of $50 \mathrm{mg}$ weekly (day 45). Fifteen subjects completed the study and there were no effects on the pharmacokinetic profile of warfarin. Varied doses of albiglutide had no effect on the International Normalized Ratio data. ${ }^{37}$

\section{Digoxin}

Healthy subjects $(n=16$, all male) were administered a single dose of digoxin $0.5 \mathrm{mg}$ alone (day 1) and again after steady-state albiglutide exposure of $50 \mathrm{mg}$ weekly (day 38). Twenty-four subjects completed the study and there were no effects of albiglutide on the pharmacokinetic profile of $\operatorname{digoxin}^{37}$ 


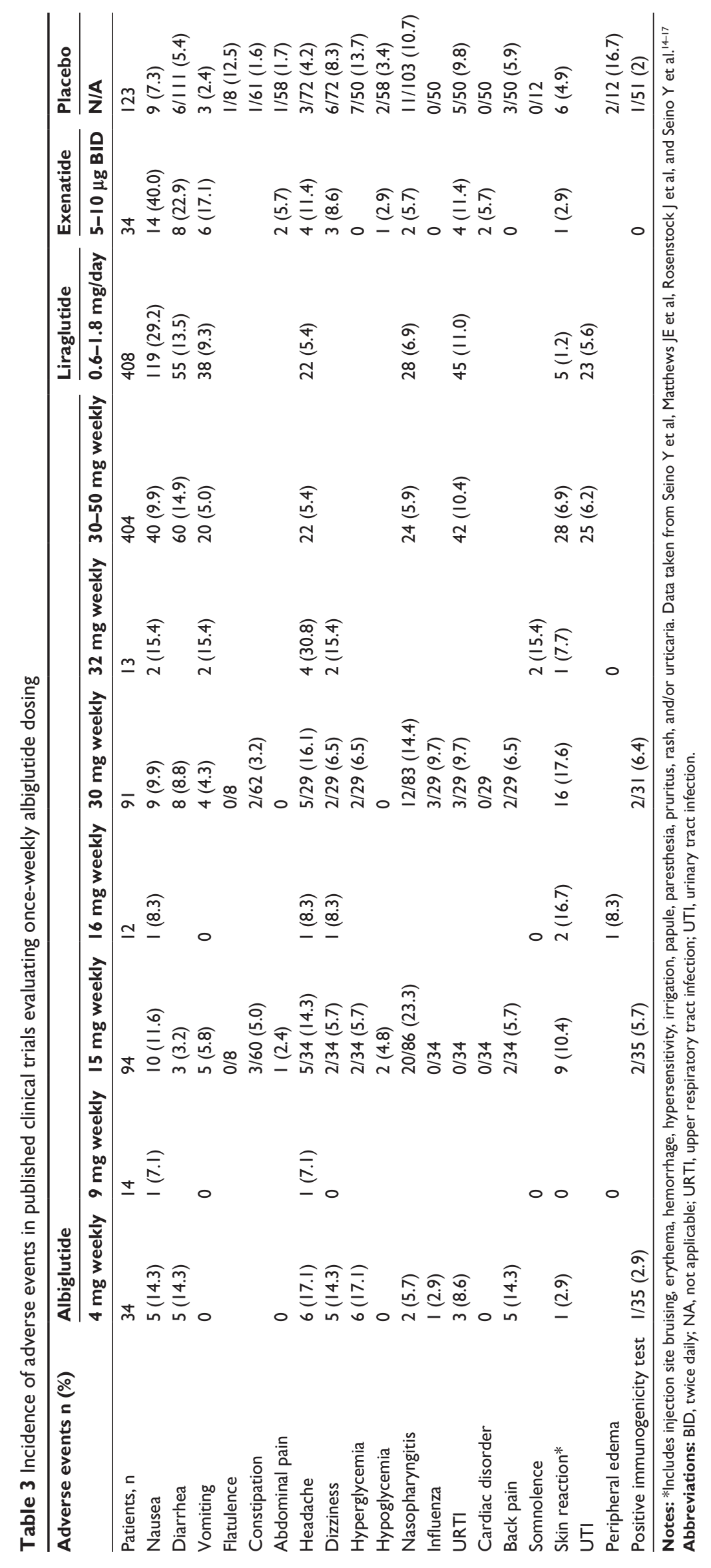




\section{Oral contraceptive pill}

This study arm was divided into three phases. Phase 1 was a run-in period to ensure all female subjects $(n=23)$ were receiving a 21-day course of oral contraception consisting of norethindrone $0.5 \mathrm{mg}$ and ethinyl estradiol $0.035 \mathrm{mg}$ daily, followed by a 7-day washout period. If subjects were already on an oral contraceptive, they were exempt from the run-in period. During Phase 2 and Phase 3, all patients received 21 days of norethindrone and ethinyl estradiol, followed by 7 days of placebo. Albiglutide $50 \mathrm{mg}$ was administered on day 26 of Phase 2 and on days 5, 12, and 19 of Phase 3. Eighteen subjects completed the study and albiglutide had no effect on the pharmacokinetic profiles of norethindrone and ethinyl estradiol. No clinically meaningful differences were found in concentrations of either luteinizing hormone or follicle-stimulating hormone. ${ }^{37}$

The study authors concluded from these data that the lack of clinically relevant pharmacokinetic or pharmacodynamic interactions means that no dose adjustments for warfarin, digoxin, or an oral contraceptive containing ethinyl estradiol and norethindrone need to be made when albiglutide is concurrently administered. This is consistent with once-weekly exenatide and liraglutide, which have no meaningful drugdrug interactions of concern. ${ }^{37}$

\section{Patient preference and adherence}

According to the 2012 American Diabetes Association/ European Association for the Study of Diabetes position statement, a patient-centered treatment strategy should be guided by an individual patient's preferences, needs, and values. ${ }^{4}$ Due to the chronic and progressive nature of type 2 diabetes mellitus, adherence to medication therapy is paramount. The importance of cost, frequency of administration, and tolerance of adverse effects are just a few of the factors that have been demonstrated to impact satisfaction and adherence to treatment in chronic disease states, including hypertension, depression, osteoporosis, and type 2 diabetes mellitus. ${ }^{39-44}$ For example, several studies have demonstrated that once-weekly dosing is associated with greater adherence than more frequent dosing in patients with osteoporosis. ${ }^{45-47}$ A survey of 1,516 patients with type 2 diabetes mellitus revealed that once-weekly injectable medications were generally viewed as an attractive option due to perceived convenience. ${ }^{48}$ Interestingly, weight loss was the characteristic most associated with willingness to take a once-weekly injectable medication.

Patient preference and adherence with use of exenatide once weekly compared with oral regimens and insulin have been nicely reviewed by Doggrell. ${ }^{48}$ Overall, treatment satisfaction scores were consistently higher with the use of exenatide once weekly when compared with exenatide twice daily, sitagliptin, and pioglitazone. ${ }^{49,50}$

To date, only one published study has evaluated treatment satisfaction with albiglutide.

The investigators of Harmony 7 assessed treatment satisfaction in 728 patients (of the 812 randomized) in the USA using the Diabetes Medication Satisfaction Questionnaire. ${ }^{51}$ This questionnaire measures satisfaction in three domains, ie, treatment burden, efficacy, and unwanted side effects. When comparing liraglutide with albiglutide, overall treatment satisfaction scores improved similarly in both groups from baseline.

Currently, there are no published trials evaluating adherence to treatment with albiglutide. However, it is likely that factors influencing adherence to medications for other chronic disease states are applicable to albiglutide. ${ }^{52}$

\section{Summary}

Albiglutide is a novel once-weekly GLP-1 receptor agonist that has demonstrated efficacy by producing favorable reductions in fasting plasma glucose, postprandial plasma glucose, and $\mathrm{HbA}_{1 \mathrm{C}}$ values. Albiglutide is the second onceweekly GLP-1 receptor agonist to be made available for patients with type 2 diabetes mellitus, and may be preferred over other GLP-1 receptor agonists because of its mild side effect profile, convenient once-weekly dosing, and efficacy in patients with renal impairment.

\section{Disclosure}

The authors report no conflicts of interest in this work.

\section{References}

1. Ross SA. Breaking down patient and physician barriers to optimize glycemic control in type 2 diabetes. Am J Med. 2013;126(9 Suppl 1): S38-S48.

2. American Diabetes Association. Standards of medical care in diabetes 2014. Diabetes Care. 2014;37 Suppl 1:S14-S80.

3. Inzucchi SE, Bergenstal RM, Buse JB, et al. Management of hyperglycemia in type 2 diabetes: a patient-centered approach. Position statement of the American Diabetes Association (ADA) and the European Association for the Study of Diabetes (EASD). Diabetologia. 2012;55 1577-1596.

4. GlaxoSmithKline. GSK receives US approval for once-weekly type 2 diabetes treatment, Tanzeum ${ }^{\mathrm{TM}}$ (albiglutide). Middlesex, UK: GlaxoSmithKline; 2014. Available from: http://www.gsk.com/media/ press-releases/2014/gsk-receives-us-approval-for-once-weekly-type-2diabetes-treatme.html. Accessed April 29, 2014.

5. Ou YC, Bloom M, Grzegorzewski KJ, et al. Pharmacokinetic and pharmacodynamic analysis of Albugon, a long-acting analog of glucagonlike peptide-1 in mice and monkeys. AAPS Pharm Sci. 2003;5:5263.

6. Bloom M, Bock J, Duttaroy A, et al. Albugon fusion protein: a long-acting analog of GLP-1 that provides lasting antidiabetic effect in animals. Diabetes Care. 2003;52:A112. 
7. Baggio LL, Huang Q, Brown TJ, Drucker DJ. A recombinant human glucagon-like peptide (GLP)-1-albumin protein (albugon) mimics peptidergic activation of GLP-1 receptor-dependent pathways coupled with satiety, gastrointestinal motility, and glucose homeostasis. Diabetes. 2004;53:2492-2500.

8. Tomkin GH. Albiglutide, an albumin-based fusion of glucagon-like peptide 1 for the potential treatment of type 2 diabetes. Curr Opin Mol Ther. 2009;11:579-588.

9. Victoza (liraglutide [rDNA origin] injection). Product information. Plainsboro, NJ, USA: Novo Nordisk; 2013.

10. Byetta (exenatide injection). Product information. Princeton, NJ, USA: Bristol-Myers Squibb Company; 2013.

11. Polonsky WH, Fisher L, Hessler D, Bruhn D, Best JH. Patient perspectives on once-weekly medications for diabetes. Diabetes Obes Metab. 2011;13:144-149.

12. Bush MA, Matthews JE, De Boever EH, et al. Safety, tolerability, pharmacodynamics and pharmacokinetics of albiglutide, a long-acting glucagon-like peptide-1 mimetic, in healthy subjects. Diabetes Obes Metab. 2009; 11:498-505.

13. Holst JJ, Deacon CF, Vilsboll T, Krarup T, Madsbad S. Glucagonlike peptide-1, glucose homeostasis, and diabetes. Trends Mol Med. 2008; $14: 161-168$

14. Seino Y, Nakajiama H, Miyahara H, et al. Safety, tolerability, pharmacokinetics and pharmacodynamics of albiglutide, a long-acting GLP1-receptor agonist, in Japanese subjects with type 2 diabetes mellitus. Curr Med Res Opin. 2009;25:3049-3057.

15. Matthews JE, Steward MW, De Boever EH, et al. Pharmacodynamics, pharmacokinetics, safety, and tolerability of albiglutide, a long-acting glucagon-like peptide-1 mimetic, in patients with type 2 diabetes. J Clin Endocrinol Metab. 2008;93:4810-4817.

16. Rosenstock J, Reusch J, Bush M, Yang F, Stewart M; Albiglutide Study Group. Potential of albiglutide, a long-acting GLP-1 receptor agonist, in type 2 diabetes: a randomized, controlled trial exploring weekly, biweekly, and monthly dosing. Diabetes Care. 2009;32:1880-1886.

17. Seino $Y$, Inagaki $N$, Miyahara $H$, et al. A randomized dose-finding study demonstrating the efficacy and tolerability of albiglutide in Japanese patients with type 2 diabetes mellitus. Curr Med Res Opin. Epub 2014 March 11 .

18. Reusch J, Stewart M, Perkins C, et al. Harmony 1 results at week 52 primary endpoint: once-weekly albiglutide vs placebo in patients with type 2 diabetes mellitus not controlled on pioglitazone \pm metformin [abstract]. Diabetes. 2013;62 Suppl 1. Available from: http://www. abstractsonline.com/Plan/ViewAbstract.aspx?sKey=0687e7c8-c97d$442 \mathrm{~b}-92$ ec-ae 505 e $051854 \&$ cKey=37d3bc28-d232-4cf4-969b-1 f061e2de0de \&mKey=89918d6d-3018-4ea9-9d4f-711f98a7ae5d. Accessed April 29, 2014.

19. Reinhardt R, Nauck MA, Stewart M, et al. Harmony 2 results at week 52 primary endpoint: once-weekly albiglutide monotherapy for patients with type 2 diabetes mellitus inadequately controlled with diet and exercise [abstract]. Available from: http://www.easdvirtualmeeting. org/resources/3898. Accessed April 29, 2014.

20. Ahrén B, Stewart M, Cirkel D, Yang F, Perry C, Johnson S. Harmony 3: 104 week efficacy of albiglutide compared with sitagliptin and glimepiride in patients with type 2 diabetes mellitus on metformin [abstract]. Diabetes. 2013;62 Suppl 1. Available from: http://www. abstractsonline.com/Plan/ViewAbstract.aspx?sKey $=0687 \mathrm{e} 7 \mathrm{c} 8$ c97d-442b-92ec-ae505e051854\&cKey=536ec2d4-682a-49ce-80c1bebcccae0900\&mKey=89918d6d-3018-4ea9-9d4f-711f98a7ae5d. Accessed April 29, 2014.

21. Pratley R, Stewart M, CirkelD, Ye J,Perry C, Carr MC. Harmony 4:52-week efficacy of albiglutide vs insulin glargine in patients with type 2 diabetes mellitus [abstract]. Diabetes. 2013;62 Suppl 1. Available from: http:// www.abstractsonline.com/Plan/ViewAbstract.aspx?sKey $=0687 \mathrm{e} 7 \mathrm{c} 8$ c97d-442b-92ec-ae505e051854\&cKey=7fda08fd-2fbc-41fa-8cff-7a5152a22488\&mKey=89918d6d-3018-4ea9-9d4f-711f98a7ae5d. Accessed April 29, 2014.
22. Stewart M, Home P, Yang F, Perry C, Carr MC. 52-week efficacy of albiglutide vs placebo and vs pioglitazone in triple therapy (background metformin and glimepiride) in patients with type 2 diabetes: Harmony 5 study [abstract]. Available from: http://www.easdvirtualmeeting.org/ resources/3872. Accessed April 29, 2014

23. Fonseca VL, Ahrén B, Chow F, et al. Once weekly GLP-1 receptor agonist albiglutide vs prandial lispro added to basal glargine in type 2 diabetes: similar glycaemic control with weight loss and less hypoglycaemia [abstract]. Available from: http://www.abstractsonline. $\mathrm{com} /$ plan/ViewAbstract.aspx $? \mathrm{mID}=2978 \&$ sKey $=880 \mathrm{~b} 06 \mathrm{fe}-7 \mathrm{bc0}$ $41 \mathrm{~d} 3-8 \mathrm{a} 60$-eccaaefd $88 \mathrm{~cd} \& \mathrm{cKey}=\mathrm{a} 4 \mathrm{a} 9 \mathrm{~d} 018-2 \mathrm{~d} 00-4 \mathrm{efe}-\mathrm{a} 431$ b34e39d6635c\&mKey=2dbfcaf7-1539-42d5-8dda-0a94abb089e8. Accessed April 29, 2014.

24. Rosenstock J, Ahrén B, Chow F, et al. Once-weekly GLP-1 receptor agonist albiglutide vs titrated prandial lispro added on to titrated basal insulin glargine in type 2 diabetes (T2D) uncontrolled on glargine plus oral agents: similar glycemic control with weight loss and less hypoglycemia [abstract]. Diabetes. 2012;61 Suppl 1:A15-A16.

25. Pratley RE, Nauck MA, Barnett AH, et al. Once-weekly albiglutide versus once-daily liraglutide in patients with type 2 diabetes inadequately controlled on oral drugs (Harmony 7): a randomised, open-label, multicentre, non-inferiority Phase 3 study. Lancet Diabetes Endocrinol. 2014;2:289-297.

26. Leiter LA, Carr MC, Stewart M, Jones-Leone AR, Yang F, Handelsman Y. Harmony 8: once weekly (QW) GLP1 agonist albiglutide (Albi) vs sitagliptin (Sita) in type 2 diabetes (T2D) pts with renal impairment (RI): week 26 results [abstract]. Diabetes. 2013;62 Suppl 1. Available from: http://www. abstractsonline.com/Plan/ViewAbstract.aspx?sKey=795037e5ca $6 e-44 a 8-8 b 54-c f b 1400 c d 733 \&$ cKey $=92$ c0e7a1-9511-45d2b37b-40dee 04cc4e4\&mKey=\%7B89918D6D-3018-4EA9-9D4F711F98A7AE5D\%7D. Accessed April 29, 2014.

27. Elashoff M, Matveyenko AV, Gier B, Elashoff R, Butler PC. Pancreatitis, pancreatic, and thyroid cancer with glucagon-like peptide-1-based therapies. Gastroenterology. 2011;141:150-156.

28. Garg R, Chen W, Pendergrass W. Acute pancreatitis in type 2 diabetes treated with exenatide or sitagliptin: a retrospective observational pharmacy claims analysis. Diabetes Care. 2010;33:2349-2354.

29. Dore DD, Bloomgren GL, Wenten M, et al. A cohort study of acute pancreatitis in relation to exenatide use. Diabetes Obes Metab. 2011;13: 559-566.

30. Gonzalez-Perez A, Schlienger RG, Rodriguez LA. Acute pancreatitis in association with type 2 diabetes and antidiabetic drugs: a populationbased cohort study. Diabetes Care. 2010;33:2580-2585.

31. US Food and Drug Administration. FDA Drug Safety Communication: FDA investigating reports of possible increased risk of pancreatitis and pre-cancerous findings of the pancreas from incretin mimetic drugs for type 2 diabetes. Silver Spring, MD, USA: US Food and Drug Administration. Available from: http://www.fda.gov/Drugs/DrugSafety/ ucm343187.htm. Accessed April 29, 2014.

32. European Medicines Agency. Investigation into GLP-1based therapies concluded. London, UK: European Medicines Agency. Available from: http://www.ema.europa.eu/ema/index. jsp?curl=pages/news_and_events/news/2013/07/news_detail_001856. jsp\&mid=WC0b01ac058004d5c1. Accessed April 29, 2014.

33. Bjerre Knudsen L, Madsen LW, Andersen S, et al. Glucagon-like peptide-1 receptor agonists activate rodent thyroid C-cells causing calcitonin release and C-cell proliferation. Endocrinology. 2010;151:1473-1486.

34. Bydureon (exenatide extended-release for injectable suspension). Package insert. Princeton, NJ, USA: Bristol-Myers Squibb Company; 2013.

35. Tanzeum (albiglutide). Product information. Wilmington, DE, USA: GlaxoSmithKline; 2014.

36. Darpo B, Zhou M, Matthews J, et al. Albiglutide does not prolong QTc interval in healthy subjects: a thorough ECG study. Diabetes Ther. Epub 2014 Feb 8. 
37. Bush M, Scott R, Watanalumlerd P, Zhi H, Lewis E. Effects of multiple doses of albiglutide on the pharmacokinetics, pharmacodynamics, and safety of digoxin, warfarin, or a low-dose oral contraceptive. Postgrad Med. 2012;124:55-72.

38. Meier JJ. GLP-1 receptor agonists for individualized treatment of type 2 diabetes mellitus. Nat Rev Endocrinol. 2012;8:728-742.

39. Libby AM, Fish DN, Hosokawa PW, et al. Patient-level medication regimen complexity across populations with chronic disease. Clin Ther. 2013;35:385-398.

40. Thom S, Poulter N, Field J, et al. Effects of a fixed-dose combination strategy on adherence and risk factors in patients with or at high risk of CVD: the UMPIRE randomized clinical trial. JAMA. 2013;310:918-929.

41. de Klerk E. Patient compliance with enteric-coated weekly fluoxetine during continuation treatment of major depressive disorder. J Clin Psychiatry. 2001;62 Suppl 22:43-47.

42. Hauber AB, Han S, Yang JC, et al. Effect of pill burden on dosing preferences, willingness to pay, and likely adherence among patients with type 2 diabetes. Patient Prefer Adherence. 2013;7:937-949.

43. de Vries ST, Keers JC, Visser R, et al. Medication beliefs, treatment complexity, and non-adherence to different drug classes in patients with type 2 diabetes. J Psychosom Res. 2014;76:134-138.

44. Reginster JY, Rabenda V, Neuprez A. Adherence, patient preference and dosing frequency: understanding the relationship. Bone. 2006;38 (4 Suppl 1):S2-6.

45. Bartl R, Goette S, Hadji P, Hammerschmidt T. Persistence and compliance with daily and weekly-administered bisphosphonates for osteoporosis treatment in Germany. Osteoporos Int. 2005;16 Suppl 3:S45.
46. Downey TW, Foltz SH, Boccuzzi SJ, Omar MA, Kahler KH. Adherence and persistence associated with the pharmacologic treatment of osteoporosis in a managed care setting. South Med J. 2006;99:570-575.

47. Penning-van Beest FJ, Erkens JA, Olson M, Herings RM. Determinants of non-compliance with bisphosphonates in women with postmenopausal osteoporosis. Curr Med Res Opin. 2008;24:1337-1344.

48. Doggrell S. Exenatide extended-release; clinical trials, patient preference, and economic considerations. Patient Prefer Adherence. 2013;7:35-45.

49. Best JH, Boye KS, Rubin RR, Cao D, Kim TH, Peyrot M. Improved treatment satisfaction and weight-related quality of life with exenatide once weekly or twice daily. Diabet Med. 2009;26:722-728.

50. Bergenstal RM, Wysham C, MacConell L, et al. Efficacy and safety of exenatide once weekly versus sitagliptin or pioglitazone as an adjunct to metformin for treatment of type 2 diabetes (DURATION-2): a randomised trial. Lancet. 2010;376:431-439.

51. Questionnaire: Brod M, Skovlund SE, Wittrup-Jensen KU. Measuring the impact of diabetes through patient report of treatment satisfaction, productivity and symptom experience. Qual Life Res. 2006;15(3):481-491.

52. Mohamed AF, Zhang J, Johnson FR, et al. Avoidance of weight gain is important for oral type 2 diabetes treatments in Sweden and Germany: patient preferences. Diabetes Metab. 2013;39:397-403.
Patient Preference and Adherence

\section{Publish your work in this journal}

Patient Preference and Adherence is an international, peer-reviewed, open access journal that focusing on the growing importance of patient preference and adherence throughout the therapeutic continuum. Patient satisfaction, acceptability, quality of life, compliance, persistence and their role in developing new therapeutic modalities and compounds to optimize

\section{Dovepress}

clinical outcomes for existing disease states are major areas of interest for the journal. This journal has been accepted for indexing on PubMed Central. The manuscript management system is completely online and includes a very quick and fair peer-review system, which is all easy to use. Visit http://www. dovepress.com/testimonials.php to read real quotes from published authors. 